\title{
Respon Pertumbuhan Setek Batang Daun Afrika (Vernonia amygdalina) dengan Penggunaan Bagian Batang dan Media Tanam
}

Growth Respone of Bitter Leaf (Vernonia amygdalina) Cuttings and Planting Medium

\author{
Siti Hilda Ma'rufah dan Sandra Arifin Aziz*
}

Departemen Agronomi dan Hortikultura, Fakultas Pertanian, Institut Pertanian Bogor (Bogor Agricultural University), Jl. Meranti, Kampus IPB Darmaga, Bogor 16680, Indonesia

Telp. \& Faks.62-251-8629353 e-mail agrohort@apps.ipb.ac.id

*Penulis Korespondensi : sandra.a.aziz@gmail.com

Disetujui : 15 Mei 2018 / Published Online 2 Januari 2019

\begin{abstract}
Bitter leaf (Vernonia amygdalina) is medicinal plant that can be used to cure Diabetes Mellitus, but there is no research about its cultivation. The objective of this research is to find the growth response of bitter leaf (Vernonia amygdalina) stem cuttings with the use of different stem and planting medium. The research was held on January to June 2017 at Cikabayan Experimental Station, and Postharvest Laboratorium, Department of Agronomy and Horticulture, Bogor Agricultural University. The design of this research was Randomized Complete Block Design (RCBD) with two factors and three replications. The first factor is the stem part consisted of tip stem, middle stem, and mature stem. The second factor is planting medium which is mixture of soil medium, rice-hull charcoal (1:1) v/v, mixture of soil, rice-hull charcoal, cow manure (1:1:1) v/v, mixture of soil, rice-hull charcoal, vermicompost $(1: 1: 1) v / v$. The results showed that the best stem section is mature and middle stem. Interaction of mature stem using mixture of soil, rice-hull charcoal, cow manure (1:1:1) $v / v$ and mixture of soil, rice-hull charcoal, vermicompost (1:1:1) v/v, and interaction of middle stem using all treatment of planting medium gave the highest variable on plant height, leaf number, branch number, stem wet weight and leaf wet weight.
\end{abstract}

Keywords: cow manure, medicinal plants, nurseries, vermicompost, Vernonia amygdalina

\begin{abstract}
ABSTRAK
Daun Afrika (Vernonia amygdalina) merupakan tanaman obat yang telah banyak dimanfaatkan untuk mengobati penyakit Diabetes Mellitus, akan tetapi belum ada penelitian tentang budi dayanya. Penelitian ini bertujuan untuk mengetahui respon pertumbuhan setek batang daun Afrika (Vernonia amygdalina) dengan penggunaan bagian batang dan jenis media tanam. Penelitian telah dilaksanakan pada bulan Januari sampai Juni 2017 di Kebun Percobaan Cikabayan dan Laboratorium Pascapanen, Departemen Agronomi dan Hortikultura, Insitut Pertanian Bogor. Rancangan yang digunakan yaitu Rancangan Kelompok Lengkap Teracak (RKLT) dengan dua faktor dan tiga ulangan. Faktor pertama yaitu bagian batang terdiri dari bagian ujung, tengah dan pangkal dari cabang tanaman. Faktor kedua yaitu media tanam terdiri dari campuran media tanah, arang sekam (1:1) v/v, campuran tanah, arang sekam, pupuk kandang sapi $(1: 1: 1) \mathrm{v} / \mathrm{v}$, campuran tanah, arang sekam, kascing $(1: 1: 1) \mathrm{v} / \mathrm{v}$. Hasil penelitian menunjukkan bahwa bagian batang terbaik yaitu bagian pangkal dan tengah batang. Interaksi bagian pangkal batang dengan campuran tanah, arang sekam, pupuk kandang sapi $(1: 1: 1) \mathrm{v} / \mathrm{v}$ dan campuran tanah, arang sekam, kascing $(1: 1: 1) \mathrm{v} / \mathrm{v}$, dan bagian tengah batang dengan semua perlakuan media tanam yang sangat nyata meningkatkan tinggi tanaman, jumlah daun, jumlah cabang, bobot basah batang dan bobot basah daun.
\end{abstract}

Kata kunci: kascing, pembibitan, pupuk kandang sapi, tanaman obat, Vernonia amygdalina 


\section{PENDAHULUAN}

Indonesia merupakan negara tropis yang kaya akan keanekaragaman hayati. Berdasarkan kelompok familinya, terdapat 203 famili tanaman obat. Secara umum, terdapat 22 famili yang memiliki spesies tanaman obat masing-masing lebih dari 20 dan 181 famili lainnya memiliki jumlah spesies masing-masing kurang dari 20. Famili Asteraceae memiliki 40 jenis spesies (Zuhud, 2009). BBPP (2012) menyatakan terdapat 9600 spesies tanaman obat yang diketahui di Indonesia, akan tetapi baru 200 spesies yang telah dimanfaatkan sebagai bahan baku industri obat tradisional dan hanya $4 \%$ yang telah dibudidayakan dari jumlah tersebut.

Salah satu komoditas biofarmaka yang belum banyak diketahui adalah daun Afrika atau dikenal sebagai Vernonia amygdalina. Menurut Orwa et al. (2009) dan Yeap et al. (2010) V. amygdalina merupakan semak tahunan yang termasuk famili Asteraceae. Tinggi tanaman tersebut dapat mencapai 2-5 $\mathrm{m}$ dengan kulit batang yang kasar disertai titik hitam yang pekat, daun berwarna hijau berbentuk bulat panjang dengan diameter tangkai $6 \mathrm{~mm}$, berbau khas dan rasa yang pahit. Yana (2015) menyatakan bahwa daun Afrika dapat tumbuh subur di lingkungan tropis maupun subtropis. Tanaman ini dapat tumbuh dengan cepat, daun yang lebat dan batang yang tinggi. Oleh karena itu, $V$. amygdalina memiliki potensi untuk dimanfaatkan dan dikembangkan lebih luas untuk menunjang kebutuhan obat tradisional.

Bagian yang banyak dimanfaatkan pada daun Afrika sebagai obat adalah bagian daun. Daun yang berkualitas dapat dihasilkan dari teknik budi daya yang tepat. Tanaman ini dapat dikembangbiakkan dengan cara setek batang. Bahan tanam dan media yang digunakan untuk setek pun perlu diperhatikan karena Hartmann and Kester (2002) menyatakan bahwa faktor-faktor yang menentukan keberhasilan setek yaitu bahan setek, jenis tanaman, ketersedian air, kandungan cadangan makanan dalam jaringan setek, hormon endogen dalam jaringan setek dan umur tanaman. Pemanfaatan bahan setek seperti bagian batang bertujuan untuk mengoptimalkan pembentukan sistem perakaran baru. Berdasarkan hasil penilitin Siregar dan Djam'an (2017); Sukarman dan Melati (2009) bahan perbanyakan setek batang yang digunakan berasal dari bahan induk bagian pangkal, tengah dan pucuk/ujung pada cabang tanaman.

Media sebagai tempat perkembangan akar merupakan salah satu faktor lingkungan yang mempengaruhi pertumbuhan setek. Media tanam harus memiliki sifat kimia, fisik, dan biologis yang baik yaitu memiliki daya menahan air yang baik, cukup hara, bebas dari gulma dan patogen, serta kemasaman tanah optimal bagi pertumbuhan. Selain itu, media tanam harus mempu menjaga kelembaban, aerasi dan drainase yang baik, tidak memiliki salinitas yang tinggi serta bebas dari hama dan penyakit tanaman (Sofyan dan Muslimin, 2007). Bahan yang dapat digunakan sebagai campuran media tanam yaitu arang sekam, pupuk kandang sapi dan kascing.

Arang sekam memilliki kemampuan mengikat air karena sifatnya yang remah dan strukturnya mudah menyimpan oksigen. Perakaran tanaman akan tumbuh dengan sempurna apabila air tercukupi dan oksigen dalam tanah tersedia (Suradal, 2014). Sementara itu, pupuk kandang yang berasal dari hasil pertanian seperti dari kotoran sapi dapat digunakan untuk menambah hara, memperbaiki sifat fisik, dan biologi tanah. Hal ini karena pupuk kandang sapi memiliki kadar selulosa yang tinggi, dan mampu menyediakan unsur hara mikro maupun makro bagi tanaman, meningkatkan porositas, mikroorganisme tanah, memudahkan pertumbuhan akar tanaman dan menyerap air yang lebih lama. Kadar hara yang terkandung dalam kotoran sapi yaitu $1.53 \% \mathrm{~N}, 0.67 \% \mathrm{P}$ dan $0.70 \%$ K (Hartatik dan Widowati, 2010). Seperti halnya arang sekam dan pupuk kandang sapi, kascing juga media tanam yang baik digunakan karena memiliki kandungan NPK (nitrogen 2-3\%, kalium $1.85-2.25 \%$ dan fosfor $1.55-2.25 \%$ ), mikronutrien, mikroba tanah yang menguntungkan, memiliki porositas tinggi serta aerasi dan kapasitas memegang air yang tinggi. Hal ini dikarenakan kascing merupakan pupuk yang berasal dari perombakan bahan-bahan organik dengan bantuan mikroorganisme dan cacing (Sinha, 2009). Hasil penelitian Oka (2007) menunjukkan pemberian kascing sebagai pupuk organik dapat memperbaiki struktur tanah dan dapat mempertahankan kestabilandan aerasi tanah. Selain mengandung unsur hara utama $(\mathrm{N}, \mathrm{P}, \mathrm{K}$, $\mathrm{Mg}$ dan $\mathrm{Ca}$ ), kascing juga banyak mengandung mikroba Azotobacter sp. sehingga kascing dapat meningkatkan kesuburan tanah. Tujuan penelitian ini adalah untuk mempelajari respon pertumbuhan setek batang daun Afrika ( $V$. amygdalina) dengan bagian batang dan jenis media tanam yang berbeda.

\section{BAHAN DAN METODE}

Penelitian telah dilaksanakan pada bulan Januari sampai Juni 2017 di Kebun Percobaan Cikabayan dan Laboratorium Pascapanen, 
Departemen Agronomi dan Hortikultura, Institut Pertanian Bogor, Dramaga, Bogor. Bahan yang digunakan terdiri dari bagian batang yang berasal dari tanaman induk daun Afrika (V. amygdalina) berumur lima tahun dan media tanam seperti pupuk tanah, arang sekam, pupuk kandang sapi dan kascing. Alat yang digunakan terdiri dari timbangan analitik, kamera, label, gunting setek, gunting, polibag, paranet dengan kerapatan 55\%. Rancangan percobaan yang digunakan dalam penelitian adalah Rancangan Kelompok Lengkap Teracak (RKLT) dengan 2 faktor. Faktor pertama yaitu bagian batang cabang tanaman yang terdiri dari 3 taraf perlakuan yaitu bagian pangkal, tengah dan ujung. Faktor kedua yaitu media tanam yang terdiri dari 3 taraf perlakuan yaitu campuran tanah, arang sekam (1:1) v/v sebagai kontrol, campuran tanah, arang sekam, pupuk kandang sapi $(1: 1: 1) \mathrm{v} / \mathrm{v}$ dan tanah, arang sekam, kascing $(1: 1: 1) \mathrm{v} / \mathrm{v}$. Terdapat 9 kombinasi perlakuan dan setiap perlakuan diulang sebanyak 3 kali serta masing-masing satuan percobaan terdiri dari 10 setek, sehingga terdapat 270 satuan percobaan.

Penelitian diawali dengan persiapan lahan terdiri dari pembersihan lahan dari gulma menggunakan cangkul dan kored, serta pemasangan paranet untuk pembibitan. Campuran media tanam dipersiapkan sesuai perbandingan yang telah ditentukan. Selanjutnya dilakukan pemotongan cabang batang tanaman daun Afrika ( $V$. amygdalina) dengan menggunakan gunting setek menjadi bagian ujung, tengah dan pangkal dengan panjang 3 buku dan membentuk sudut $45^{\circ}$. Bagian yang sudah dipotong kemudian direndam dalam larutan fungisida Dithane M-45 konsentrasi $1 \mathrm{~g} \mathrm{~L}^{-1}$ sebelum ditanam. Penanaman dilakukan pada sore hari dimulai dengan membuat lubang tanam pada polibag berukuran $15 \mathrm{~cm} \times 20 \mathrm{~cm}$ yang sudah diisi media tanam campuran sesuai perlakuan. Setek ditanam dengan kedalaman kurang lebih $1 / 3$ panjang setek pada sejumlah satuan percobaan sebanyak 270 polibag. Pengamatan dilakukan setiap 2 minggu sekali dan parameter yang diamati meliputi daya tumbuh setek, jumlah cabang, jumlah daun, tinggi tanaman, bobot basah $\left(\mathrm{g} \operatorname{tanaman}^{-1}\right)$ dan uji kandungan pigmen daun (karotenoid, antosianin, klorofil a, klorofil b dan total).

\section{HASIL DAN PEMBAHASAN}

\section{Kondisi Umum Percobaan}

Curah hujan di Bogor berkisar 130-526 mm bulan $^{-1}$ pada bulan Januari hingga Mei 2017 (BMKG, 2017), sehingga mampu memberikan suplai air yang cukup untuk masa awal pertumbuhan setek selama di lapangan. Hasil penelitian Nurkhasanah et al. (2013) menunjukkan bahwa pemberian air berpengaruh nyata terhadap persentase keberhasilan setek. Sementara suhu rata-rata berkisar 25-26,4 oC dan kelembaban berkisar 84-88\% (BMKG, 2017). Kelembaban yang tinggi saat penyetekan dapat mempertahankan setek dari kekeringan dan menghambat laju transpirasi (Yulistyani, 2014).

Hama yang ditemui di pertanaman $V$. amygdalina adalah dari famili Curculionidae namun penyerangannya hanya terdapat pada beberapa perlakuan pertanaman saja dan tidak menimbulkan kerusakan yang parah. Adapun gulma yang sering mendominasi di sekitar area penelitian yaitu Mimosa pudica, Cyperus rotundus dan Paspalum conjugatum. Penanganan gulma dilakukan dengan cara dicabut dengan tangan atau dibersihkan menggunakan cangkul agar tidak mengganggu tanaman $V$. amygdalina.

\section{Daya Tumbuh Stek}

Faktor perlakuan tidak memberikan pengaruh nyata terhadap persentase tumbuh setek daun Afrika. Meskipun demikian, hasil penelitian pada Tabel 1 menunjukkan bahwa persentase tumbuh sudah mencapai $100 \%$ pada 4 MST. Perlakuan bagian ujung batang dan bagian tengah batang lebih tinggi dibandingkan bagian pangkal batang sebesar $18,32 \%$ dan $4,23 \%$ terhadap persentase tumbuh tunas pada setek batang daun Afrika. Hal ini disebabkan karena pengaruh hormon endogen yaitu auksin yang mampu mendorong terbentuknya tunas (Hartmann and Kester, 2002). Selain itu, persediaan karbohidrat dan nitrogen juga sangat menentukan pertumbuhan akar dan tunas pada bahan setek(Suryaningsih, 2004). Persentase tumbuh setek batang bagian ujung lebih tinggi dibandingkan pangkal dan tengah karena bahan

Tabel 1. Pengaruh bagian batang dan media tanam terhadap persentase tumbuh

\begin{tabular}{|c|c|c|c|c|c|}
\hline \multicolumn{3}{|c|}{ Bagian Batang } & \multicolumn{3}{|c|}{ Media Tanam } \\
\hline Pangkal & Tengah & Ujung & $\begin{array}{l}\text { Tanah dan Arang } \\
\text { Sekam }(1: 1) \mathrm{v} / \mathrm{v}\end{array}$ & $\begin{array}{l}\text { Tanah, Arang Sekam dan } \\
\text { Pukan Sapi }(1: 1: 1) \mathrm{v} / \mathrm{v} / \mathrm{v}\end{array}$ & $\begin{array}{c}\text { Tanah, Arang Sekam dan } \\
\text { Kascing }(1: 1: 1) \mathrm{v} / \mathrm{v} / \mathrm{v}\end{array}$ \\
\hline \multirow{3}{*}{78.88} & \multicolumn{5}{|c|}{ Tunas tumbuh (\%) pada 2 MST } \\
\hline & 82.22 & 93.33 & 81.11 & 86.66 & 86.66 \\
\hline & & \multicolumn{4}{|c|}{ Tunas tumbuh (\%) pada 4 MST . } \\
\hline 100.00 & 100.00 & 100.00 & 100.00 & 100.00 & 100.00 \\
\hline
\end{tabular}


setek muda (ujung) jaringan muda (meristem) yang belum terdeferensiasi lebih mudah mengalami proses diferensiasi dalam pembentukan tunas (Weaver, 1972).

Media campuran tanah, arang sekam, pupuk kandang sapi $(1: 1: 1) \mathrm{v} / \mathrm{v}$ dan campuran tanah, arang sekam, kascing $(1: 1: 1) \mathrm{v} / \mathrm{v} 6.84 \%$ lebih tinggi dibandingkan campuran media tanah dan sekam/kontrol (1:1) $\mathrm{v} / \mathrm{v}$ terhadap persentase tumbuh tunas. Hayati et al. (2012) menyatakan bahwa campuran media yang tepat dalam penyediaan aerasi tanah mempengaruhi tunas setek berkembang dengan baik karena sifat fisik dan kimia media yang ideal dapat meningkatkan fungsinya sebagai penyedia unsur hara, sirkulasi udara, pengikat air yang baik untuk penunjang pertumbuhan tunas ataupun akar.

\section{Pengamatan Fase Pertumbuhan Stek}

\section{Tinggi Tanaman}

Kombinasi perlakuan bagian batang dan media tanam berpengaruh sangat nyata terhadap tinggi tanaman pada 12 MST. Hasil pengamatan terhadap tinggi tanaman menunjukkan bahwa bagian pangkal batang memiliki tinggi tanaman yang baik pada campuran media tanah, arang sekam, pupuk sapi $(1: 1: 1) \mathrm{v} / \mathrm{v}$ dan campuran media tanah, sekam, kascing $(1: 1: 1) \mathrm{v} / \mathrm{v}$. Tanaman yang menggunakan campuran media tanah, arang sekam, pupuk sapi $(1: 1: 1) \mathrm{v} / \mathrm{v}$ dan campuran media tanah, arang sekam, kascing $(1: 1: 1) \mathrm{v} / \mathrm{v}$ memberikan hasil yang lebih tinggi dibandingkan campuran media tanah, arang sekam (1:1) v/v sebesar $45.26 \%$ dan $68.28 \%$. Sementara perlakuan pada bagian tengah batang memberikan hasil yang tidak berbeda nyata pada semua perlakuan campuran media tanam sehingga dapat dikatakan memiliki tinggi yang baik pada semua campuran media tanam (Tabel 2).

Menurut Sathianarayanan dan khan (2008) pupuk kandang sapi dan kascing dapat memperbaiki kesuburan tanah serta meningkatkan nutrisi tanah. Sumarno (2010) menyatakan bahwa kadar N pada kascing dapat memberikan efek menstimulir pertumbuhan pada fase vegetatif dan merupakan unsur pengatur absorpsi kalium (K) dan Phosphor (P). Kemudian pernyatan diperkuat oleh Arifah (2014) komposisi kascing dapat mendorong aktivitas metabolisme tanaman pada bagian yang dapat berperan dalam perkembangan sel terutama yang berkaitan dengan perpanjangan sel sehingga berpengaruh terhadap tinggi tanaman. Selain itu Handajaningsih et al. (2013) menyatakan bahwa zat pengatur tumbuh seperti auksin dalam vermikompos berperan dalam pemanjangan sel yang dapat meningkatkan tinggi tanaman.

\section{Jumlah daun}

Jumlah daun merupakan indikator yang menunjukkan besarnya fotosintat yang dihasilkan tanaman dalam menghasilkan organ jaringan tanaman maupun organ reproduksi yang erat kaitannya dengan nilai produktivitas tanaman. Peningkatan jumlah daun disebabkan oleh ketersediaan unsur hara yang diberikan dan nitrogen merupakan unsur penting dalam yang diperlukan dalam pembentukan daun (Manahan et al., 2016).

Analisis sidik ragam menunjukkan bahwa kombinasi perlakuan antara bagian batang dan media tanam yang digunakan pada setek $V$. amygdalina memberikan pengaruh yang sangat nyata terhadap jumlah daun. Berdasarkan Tabel 2 perlakuan pangkal batang hanya menghasilkan jumlah daun yang baik pada campuran media

Tabel 2. Pengaruh bagian batang dan media tanam terhadap persentase tumbuh

\begin{tabular}{|c|c|c|c|}
\hline \multirow[b]{2}{*}{$\begin{array}{l}\text { Bagian } \\
\text { Batang }\end{array}$} & \multicolumn{3}{|c|}{ Media Tanam } \\
\hline & $\begin{array}{l}\text { Tanah dan Arang Sekam } \\
(1: 1) \mathrm{v} / \mathrm{v}\end{array}$ & $\begin{array}{l}\text { Tanah, Arang Sekam dan Pukan } \\
\text { Sapi }(1: 1: 1) \mathrm{v} / \mathrm{v} / \mathrm{v}\end{array}$ & $\begin{array}{l}\text { Tanah, Arang Sekam dan } \\
\text { Kascing }(1: 1: 1) \mathrm{v} / \mathrm{v} / \mathrm{v}\end{array}$ \\
\hline & \multicolumn{3}{|c|}{ Tinggi Tanaman $(\mathrm{cm})$ pada $12 \mathrm{MST}$} \\
\hline Pangkal & $57.78 \mathrm{~d}$ & $83.93 \mathrm{abc}$ & $97.23 \mathrm{a}$ \\
\hline Tengah & $85.32 \mathrm{abc}$ & $92.70 \mathrm{ab}$ & $76.79 \mathrm{abcd}$ \\
\hline \multirow[t]{2}{*}{ Ujung } & $66.79 \mathrm{dc}$ & $74.79 \mathrm{bcd}$ & $67.91 \mathrm{dc}$ \\
\hline & \multicolumn{3}{|c|}{ Jumlah Daun (helai) pada 12 MST } \\
\hline Pangkal & $33.7 \mathrm{~d}$ & $41.0 \mathrm{bcd}$ & $55.4 \mathrm{a}$ \\
\hline Tengah & $53.0 \mathrm{ab}$ & $48.5 \mathrm{abc}$ & $43.5 \mathrm{abcd}$ \\
\hline \multirow[t]{2}{*}{ Ujung } & $37.4 \mathrm{~cd}$ & $40.5 \mathrm{~cd}$ & $34.63 \mathrm{~d}$ \\
\hline & & Jumlah Cabang (cabang) pada 4 MST & \\
\hline Pangkal & $2.7 \mathrm{abc}$ & $3.3 \mathrm{a}$ & $3.3 \mathrm{a}$ \\
\hline Tengah & $3.0 \mathrm{ab}$ & $3.0 \mathrm{ab}$ & $2.3 \mathrm{bc}$ \\
\hline Ujung & $2.0 \mathrm{c}$ & $2.0 \mathrm{c}$ & $2.0 \mathrm{c}$ \\
\hline
\end{tabular}

Keterangan : Angka yang diikuti huruf yang berbeda pada peubah yang sama menunjukkan berbeda nyata pada uji DMRT taraf $5 \%$. 
tanah, arang sekam, kascing $(1: 1: 1) \mathrm{v} / \mathrm{v}$ dan $64.39 \%$ lebih banyak menghasilkan daun dari perlakuan campuran media tanah, arang sekam (1:1) $\mathrm{v} / \mathrm{v}$, sedangkan bagian tengah batang menghasilkan jumlah daun yang tidak berbeda nyata terhadap semua perlakuan campuran media tanam sehingga dapat dikatakan memiliki jumlah daun yang baik pada semua perlakuan campuran media tanam.

\section{Jumlah cabang}

Penggunaan bagian batang dan media tanam memberikan pengaruh yang sangat nyata pada 4 MST. Perlakuan pada bagian pangkal batang menghasilkan jumlah cabang yang baik pada semua perlakuan campuran media tanam. Perlakuan campuran tanah, arang sekam, pupuk kandang sapi (1:1:1) v/v maupun campuran tanah, arang sekam, kascing (1:1:1) v/v menghasilkan rata-rata jumlah cabang tidak berbeda nyata sebanyak 3.3 cabang dan $22.22 \%$ lebih banyak dibandingkan campuran media tanah, arang sekam (1:1) v/v. Sementara penggunaan bagian tengah batang menghasilkan jumlah cabang yang baik pada perlakuan campuran media tanah, sekam (1:1) $\mathrm{v} / \mathrm{v}$ dan campuran tanah, arang sekam, pupuk kandang sapi $(1: 1: 1) \quad \mathrm{v} / \mathrm{v} \quad$ serta menghasilkan rata-rata jumlah cabang yang tidak berbeda nyata sebanyak 3.0 cabang (Tabel 2). Menurut Wulandari et al. (2014) cahaya dan unsur hara yang mencukupi dapat meningkatkan jumlah cabang dan jumlah daun pada tanaman. Dengan demikian, dapat diduga bahwa penggunaan media pupuk kandang sapi dan kascing dapat menambah nutrisi pada campuran media tanah dan sekam sebagai penunjang pertumbuhan setek.

\section{Luas daun}

Hasil sidik ragam menunjukkan bahwa penggunaan bagian batang dan media tanaman pada setek daun afrika tidak memberikan pengaruh nyata terhadap luas daun pada 14 MST. Bagian pangkal batang dan ujung batang yang dikombinasikan dengan perlakuan campuran media tanah, arang sekam, kascing $(1: 1: 1) \mathrm{v} / \mathrm{v}$ memiliki luas daun lebih tinggi sebesar $203.57 \%$ dan $178.93 \%$ dibandingkan campuran media tanah, arang sekam (1:1) v/v. Bagian tengah batang menghasilkan luas daun tertinggi pada perlakuan campuran media tanah, arang sekam, sapi $(1: 1: 1) \quad \mathrm{v} / \mathrm{v}$ dan $55.25 \%$ lebih tinggi dibandingkan campuran media tanah, arang sekam (1:1) v/v (Tabel 3).

Luas daun akan mempengaruhi kunatitas penyerapan cahaya pada tanaman. Jika cahaya dan unsur hara mencukupi, jumlah cabang dan jumlah daun akan meningkat. Tanaman akan meningkatkan laju pertumbuhan daunnya agar dapat menangkap cahaya secara optimal sehingga fotosintesis dapat berjalan dengan lancar (Setyanti et al., 2013).

\section{Bobot Basah Batang dan Daun}

Bobot basah batang dan daun berpengaruh sangat nyata pada 14 MST. Bobot basah batang per tanaman dengan penggunaan bagian pangkal batang menghasilkan bobot basah batang yang baik pada campuran tanah, sekam, pupuk kandang sapi $(1: 1: 1) \mathrm{v} / \mathrm{v}$ dan media campuran campuran tanah, sekam, kascing (1:1:1) v/v (Tabel 4). Media campuran media tanah, arang sekam, pupuk sapi $(1: 1: 1) \quad \mathrm{v} / \mathrm{v} 72.40 \%$ lebih tinggi dibandingkan campuran media tanah, arang sekam (1:1) v/v sedangkan campuran media tanah, arang sekam, kascing (1:1:1) $\quad \mathrm{v} / \mathrm{v} \quad 90.06 \%$ lebih tinggi dibandingkan campuran media tanah, arang sekam (1:1) $\mathrm{v} / \mathrm{v}$. Bagian tengah batang menghasilkan bobot basah batang yang baik pada campuran media tanah, arang sekam (1:1) v/v dan campuran tanah, sekam, pupuk kandang sapi $(1: 1: 1) \mathrm{v} / \mathrm{v}$. Bagian ujung batang menghasilkan bobot basah batang yang baik pada campuran media tanah, sekam, pupuk kandang sapi $(1: 1: 1) \mathrm{v} / \mathrm{v}$ dan $50.49 \%$ lebih tinggi dibandingkan dengan campuran media tanah, arang sekam $(1: 1) \mathrm{v} / \mathrm{v}$.

Menurut Pujisiswanto dan Pangaribuan (2008) tingginya kadar nitrogen pada jaringan tanaman akan mengakibatkan tanaman memiliki daun yang lebar dengan warna yang lebih hijau sehingga fotosintesis dapat berjalan dengan baik. Hasil fotosintesis digunakan untuk perkembangan dan pertumbuhan tanaman seperti pertambahan ukuran panjang tanaman serta pembentukan cabang dan daun baru. Hal ini diduga dapat berpengaruh terhadap bobot basah dan semakin tinggi fotosintat yang ditranslokasikan maka bobot basah daun maupun batang akan meningkat

Tabel 3 Luas daun pertumbuhan setek batang daun Afrika

\begin{tabular}{lccc}
\hline \multirow{2}{*}{$\begin{array}{c}\text { Bagian } \\
\text { Batang }\end{array}$} & \multicolumn{3}{c}{ Media Tanam } \\
\cline { 2 - 4 } & $\begin{array}{c}\text { Tanah dan Arang Sekam } \\
(1: 1) \mathrm{v} / \mathrm{v}\end{array}$ & $\begin{array}{c}\text { Tanah, Arang Sekam dan Pukan } \\
\text { Sapi }(1: 1: 1) \mathrm{v} / \mathrm{v} / \mathrm{v}\end{array}$ & $\begin{array}{c}\text { Tanah, Arang Sekam dan } \\
\text { Kascing }(1: 1: 1) \mathrm{v} / \mathrm{v} / \mathrm{v}\end{array}$ \\
\hline & $\ldots \ldots \ldots \ldots \ldots \ldots$ Luas Daun $\left(\mathrm{cm}^{2} \tan ^{-1}\right)$ pada $14 \mathrm{MST}$ & $\ldots \ldots \ldots \ldots \ldots \ldots \ldots \ldots \ldots \ldots \ldots \ldots \ldots$ \\
Pangkal & 3.643 & 9.626 & 11.059 \\
Tengah & 4.474 & 6.946 & 6.474 \\
Ujung & 3.920 & 7.265 & 10.934 \\
\hline
\end{tabular}


Tabel 4. Pengaruh interaksi antara bagian batang dan media tanam terhadap bobot basah batang dan daun pada 14 MST

\begin{tabular}{|c|c|c|c|}
\hline \multirow[b]{2}{*}{$\begin{array}{l}\text { Bagian } \\
\text { Batang }\end{array}$} & \multicolumn{3}{|c|}{ Media Tanam } \\
\hline & $\begin{array}{l}\text { Tanah dan Arang Sekam } \\
(1: 1) \mathrm{v} / \mathrm{v}\end{array}$ & $\begin{array}{c}\text { Tanah, Arang Sekam dan Pukan } \\
\text { Sapi }(1: 1: 1) \mathrm{v} / \mathrm{v} / \mathrm{v}\end{array}$ & $\begin{array}{c}\text { Tanah, Arang Sekam dan } \\
\text { Kascing }(1: 1: 1) \mathrm{v} / \mathrm{v} / \mathrm{v}\end{array}$ \\
\hline & \multicolumn{3}{|c|}{ Bobot Basah Batang $\left(\mathrm{g} \tan ^{-1}\right) \ldots \ldots \ldots \ldots \ldots \ldots \ldots \ldots$} \\
\hline Pangkal & $86.85 \mathrm{c}$ & $149.73 \mathrm{a}$ & $165.07 \mathrm{a}$ \\
\hline Tengah & $142.71 \mathrm{ab}$ & $156.08 \mathrm{a}$ & $98.87 \mathrm{bc}$ \\
\hline \multirow[t]{2}{*}{ Ujung } & $77.99 \mathrm{dc}$ & $117.37 \mathrm{abc}$ & $88.78 \mathrm{c}$ \\
\hline & & Bobot Basah Daun $\left(\mathrm{g} \mathrm{tan}^{-1}\right)$ & \\
\hline Pangkal & $43.94 \mathrm{~d}$ & $66.29 \mathrm{abc}$ & $80.04 \mathrm{a}$ \\
\hline Tengah & $74.99 \mathrm{a}$ & $77.47 \mathrm{a}$ & $65.43 \mathrm{abc}$ \\
\hline Ujung & $47.55 \mathrm{bcd}$ & $69.90 \mathrm{ab}$ & $36.29 \mathrm{~d}$ \\
\hline
\end{tabular}

Keterangan: Angka yang diikuti huruf yang berbeda pada peubah yang sama menunjukkan berbeda nyata pada uji DMRT taraf $5 \%$.

dan penambahan pupuk kandang sapi dan kascing dapat menambah serapan hara oleh tanaman, metabolisme dan translokasinya dalam tanaman.

\section{Kandungan Pigmen Daun}

Hasil uji $F$ pigmen pada 14 MST menunjukkan bahwa kombinasi perlakuan antara bagian batang dan media tanaman setek batang daun afrika menunjukkan pengaruh yang tidak nyata (lampiran 4). Menurut Maulid dan Laily (2015) kadar pigmen klorofi a, klorofil b, total klorofil dan senyawa antosianin yang berbeda dihasilkan pada tingkat umur daun yang berbeda. Tabel 5 menunjukkan bahwa kadar pigmen klorofil a, klorofil $\mathrm{b}$ dan total klorofil tertinggi terdapat pada kombinasi perlakuan bagian tengah batang setek daun afrika dengan campuran media tanah, arang sekam, kascing (1:1:1) v/v menghasilkan kadar pigmen lebih tinggi dibandingkan campuran media tanah, arang sekam (1:1) v/v sebesar 12.27, 15.65 dan 13.23\%.

Selain itu, kadar karotenoid pada Tabel 5 menghasilkan kadar pigmen tertinggi terdapat pada perlakuan antara bagian tengah batang dengan campuran media tanah, arang sekam, kascing $(1: 1: 1) \mathrm{v} / \mathrm{v}$ juga yaitu $8.07 \%$ lebih tinggi dibandingkan dengan campuran media tanah, arang sekam (1:1) $\mathrm{v} / \mathrm{v}$. Sementara kadar antosianin tertinggi yaitu pada kombinasi perlakuan antara bagian ujung batang dengan campuran media tanah, arang sekam, pukan sapi $(1: 1: 1) \quad \mathrm{v} / \mathrm{v} \quad$ sebesar $28.36 \%$ lebih tinggi dibandingkan dengan campuran media tanah, arang sekam $(1: 1) \mathrm{v} / \mathrm{v}$.

Tabel 5. Pengaruh bagian batang dan media tanam terhadap kandungan pigmen daun

\begin{tabular}{|c|c|c|c|}
\hline \multirow[b]{2}{*}{$\begin{array}{l}\text { Bagian } \\
\text { Batang }\end{array}$} & \multicolumn{3}{|c|}{ Media Tanam } \\
\hline & $\begin{array}{l}\text { Tanah dan Arang Sekam } \\
(1: 1) \mathrm{v} / \mathrm{v}\end{array}$ & $\begin{array}{c}\text { Tanah, Arang Sekam dan Pukan } \\
\text { Sapi }(1: 1: 1) \mathrm{v} / \mathrm{v} / \mathrm{v}\end{array}$ & $\begin{array}{c}\text { Tanah, Arang Sekam dan } \\
\text { Kascing }(1: 1: 1) \mathrm{v} / \mathrm{v} / \mathrm{v}\end{array}$ \\
\hline & $\ldots \ldots \ldots \ldots \ldots \ldots$ & $\ldots \ldots$. Klorofil a $\left(\mathrm{mg} \mathrm{g}^{-1}\right) \ldots \ldots \ldots \ldots$ & (1) \\
\hline Pangkal & 1.9634 & 2.0425 & 2.0116 \\
\hline Tengah & 1.8940 & 1.7414 & 2.1264 \\
\hline \multirow[t]{2}{*}{ Ujung } & 1.8125 & 1.7546 & 1.9152 \\
\hline & & Klorofil b $\left(\mathrm{mg} \mathrm{g}^{-1}\right)$ & \\
\hline Pangkal & 0.8052 & 0.8207 & 0.8077 \\
\hline Tengah & 0.7493 & 0.7238 & 0.8666 \\
\hline \multirow{2}{*}{ Ujung } & 0.7318 & 0.7423 & 0.7862 \\
\hline & & .. Total Klorofil a ( $\left.\mathrm{mg} \mathrm{g}^{-1}\right)$ & \\
\hline Pangkal & 2.7685 & 2.8633 & 2.8194 \\
\hline Tengah & 2.6433 & 2.4653 & 2.9930 \\
\hline \multirow[t]{2}{*}{ Ujung } & 2.5443 & 2.4969 & 2.7014 \\
\hline & & Antosianin $\left(\mathrm{mg} \mathrm{g}^{-1}\right)$ & \\
\hline Pangkal & 0.0880 & 0.0722 & 0.0736 \\
\hline Tengah & 0.0615 & 0.0619 & 0.0913 \\
\hline \multirow{2}{*}{ Ujung } & 0.0797 & 0.1023 & 0.0785 \\
\hline & & Karotenoid $\left(\mathrm{mg} \mathrm{g}^{-1}\right)$ & \\
\hline Pangkal & 0.5752 & 0.5422 & 0.5626 \\
\hline Tengah & 0.5732 & 0.4916 & 0.6195 \\
\hline Ujung & 0.5415 & 0.5085 & 0.5211 \\
\hline
\end{tabular}


Hasil pengujian kadar pigmen dari seluruh perlakuan menunjukkan bahwa terdapat kadar pigmen tertinggi pada daun afrika yaitu pigmen klorofil a dibandingkan kadar pigmen lainnya. Hal ini disebabkan warna dominan dari daun tanaman ini berwarna hijau sedang hingga tua sehingga kadar pigmen yang tinggi dihasilkan dari pengaruh pigmen klorofil. Menurut Colby (2007) klorofil adalah pigmen berwarna hijau yang menyerap cahaya merah dan biru serta terdapat dalam kloroplas bersama-sama dengan karoten dan xantofil pada makhluk hidup yang memiliki kemampuan berfotosintesis dan pada tanaman hijau terdapat dua bentuk klorofil yaitu klorofil a dan klorofil b. sedangakan Lobato et. al. (2009) menyatakan bahwa kedua pigmen tersebut berperan penting dalam penyerapan cahaya selama fotosintesis. Klorofil a merupakan pigmen fotosintesis utama sementara klorofil $b$ sebagai pigmen aksesori yang mengumpulkan energi dan meneruskannya ke klorofil a (Egink et al., 2001).

Berdasarkan Tabel 2, Tabel 3 dan Tabel 4, bagian batang dan media tanam terbaik terdapat pada pilihan bagian pangkal batang yang dikombinasikan dengan media tanam campuran pupuk kandang sapi dan campuran kascing sedangkan bagian tengah batang menghasilkan pertumbuhan bibit yang baik pada semua perlakuan campuran media tanam.

Bibit hasil perbanyakan setek dinyatakan berhasil jika membentuk tajuk dan perakaran yang baik. Menurut Santoso et al. (2008) manifestasi dari pertumbuhan akar maupun tunas (tajuk) adalah pada persentase setek yang berhasil menjadi bibit berkualitas dan daya adaptasinya setelah dipindahkan ke lapangan. Hal ini didukung oleh komposisi kimia yang berbeda dari setek bagian pangkal, tengah dan ujung batang pada setek daun Afrika ( $V$. amygdalina) yang menunjukkan adanya tingkat akumulasi cadangan makanan berupa kabohidrat dan nitrogen, kedua cadangan makanan tersebut dapat mendukung pertumbuhan pada bagian tajuk dan akar serta menentukan pertumbuhan dan perkembangan bibit. Gehlot et al. (2014) dan Hartmann et al. (2002) menyatakan bahwa tingkat pertumbuhan setek batang tergantung pada variasi umur, media tanam, status nutrisi kandungan cadangan makanan dan hormon endogen dalam jaringan setek.

Selain itu, adanya pengaruh penambahan media tanam seperti pupuk kandang sapi dan kascing dapat menambah nutrisi bagi tanaman untuk penunjang pertumbuhan. Maji et al. (2016) menyatakan bahwa kascing memiliki efek positif pada nutrisi tanaman, fotosintesis, kandungan klorofil daun, dan meningkatkan kandungan nutrisi dari berbagai komponen tanaman (akar, tunas dan buah). Tingginya persentase asam humat dalam kascing berkontribusi terhadap kesehatan tanaman karena meningkatkan sintesis senyawa fenolik seperti antosianin yang termasuk senyawa flavonoid yang dapat meningkatkan kualitas tanaman dan mencegah hama atau penyakit. Sementara kotoran sapi menurut Raj et al. (2014) sebagai bio-fertilizer dapat meningkatkan kandungan bahan organik tanah sebagai alternatif yang sangat efektif untuk meningkatkan produktivitas dalam pemeliharaan kesehatan tanah dan meningkatkan populasi mikroba.

\section{KESIMPULAN}

Hasil penelitian menunjukkan bahwa bagian batang terbaik yaitu bagian pangkal dan tengah. Interaksi bagian pangkal batang dengan campuran tanah, arang sekam, pupuk kandang sapi $(1: 1: 1)$ $\mathrm{v} / \mathrm{v}$ maupun campuran tanah, arang sekam, kascing (1:1:1) $\mathrm{v} / \mathrm{v}$ dan bagian tengah batang dengan semua perlakuan media tanam yang sangat nyata meningkatkan tinggi tanaman, jumlah daun, jumlah cabang, bobot basah batang dan bobot basah daun.

\section{DAFTAR PUSTAKA}

Arifah, S.M. 2014. Analisis komposisi pakan cacing Lumbricus sp. terhadap kualitas kascing dan aplikasinya pada tanaman sawi. J. Gamma. 9(2): 63-72.

[BBPP] Balai Besar Pelatihan Pertanian Lembang. 2012. Potensi tanaman obat di indonesia. http://www.bbpplembang.info. [ 8 April 2016].

[BMKG] Badan Meteorologi Klimatologi dan Geofisika. 2017. Data iklim harian 2017. Stasiun Klimatologi Bogor, Bogor.

Colby. 2007. Identification of leaf pigments. J. Res. Meth.9: 8-10.

Egingk, L.L., H. Park, J.K. Hoober. 2001. The Role of Chlorophyll $b$ in Photosynthesis: Hypotesis. BMC Plant Biology, Canada.

Gehlot, A., S. Arya, I.D. Arya. 2014. Vegetative propagation of Azadirachta indica A JUSS (NEEM) troughh cuttings: a review. Natva. Sinop. 2(4): 239-246.

Handajaningsih, M., E.I. Sukarjo, N. Lidiawati. 2013. Pertumbuhan awal mahkota dewa (Phaleriamacrocarpa) pada beberapa dosis 
vermikomposdan intensitas naungan. AGROTOP. 3(2): 43-50.

Hartatik, W., L.R. Widowati. 2010. Pupuk kandang. http://www. balittanah.litbang. pertanian.go.id. [27 November 2016].

Hartmann, H.T., D.E. Kester, F.T. Davies, R.L. Geneve. 2002. Hartmann and Kester's Plant Propagation: Principle and Practice 8th ed. Prentice Hall Inc, New Jersey.

Hayati, E., Sabaruddin, Rahmawati. 2012. Pengaruh jumlah mata tunas dan komposisi media tanam terhadap pertumbuhan setek tanaman jarak pagar (Jatropha curcas L.). J. Agrista. 16(3): 129-134.

Lobato, A.K.S., G.K. Coimbra, M.A.M. Neto, R.C.L. Costa, B.G.S. Filho, C.F.O. Neto, L.M. Luz, A.G.T. Barreto, B.W.F. Pereira, G.A.R. Alves, B.S. Monteiro, C.A Marochio. 2009. Protective action of silicon on water relations and photosynthetic pigments in pepper plants induced to water deficit. J. Bio Sci. 4: 617-623.

Maji, D., P. Misra, S. Singh, A. Kalra. 2016. Humic acid rich vermicompost promotes plant growth by improving microbial community structure of soil as well as root nodulation and mycorrhizal colonization in the roots of Pisum sativum. J. Apsoil.110: 97-108.

Manahan, S., Idwar, Wardati. 2016. Pengaruh pupuk NPK dan kascing terhadap pertumbuhan kelapa sawit (Elaeis guineensis Jacq) fase main nursery. JOM. Faperta. 3(3): 1-10.

Maulid, R.R., A.N. Laily. 2015. Kadar total pigmen klorofil dan senyawa antosianin ekstrak Kastuba (Euphorbia pulcherrima) berdasarkan umur daun. Dalam: M. Ramli, Nurmiyati, D.P. Sari, A. Saputra (eds.). Towards Conservation and Sustainable Use af Natural Resource. A Perspective of Education Biology, Geography and Enviromental Science. Seminar Konservasi dan Pemanfaatan Sumber Daya Alam. Surakarta, 13 januari 2015.

Nurkhasanah, N., K.P. Wicaksono, E. Widaryanto. Studi pemberian air dan tingkat naungan terhadap pertumbuhan bibit tanaman cabe jamu (piper retrofractum vahl.). J. Prod.Tan. 1(4): 325332.

Oka, A.A. 2007. Pangaruh pupuk kascing terhadap pertumbuhan tanaman kangkung darat (Ipomea reptans Poir). J. Sains MIPA. 13(1):26-28.

Orwa, C., A. Matua, R. Kindt, R. Jamnadass, S. Anthony. 2009. Agroforestree Database: a tree reference and selection guide version 4.0. http://www.worldagroforestry.org/sites/ treedbs/treedatabases.asp. $\left[\begin{array}{ll}19 & \text { September }\end{array}\right.$ 2017].

Pujisiswanto, H., D. Pangaribuan. 2008. Pengaruh dosis kompos pupuk kandang sapi terhadap pertumbuhan dan produksi buah tomat. Dalam: Y. Wijaya, Anwar, Ardiansyah (eds.). Peran Strategis Sains dan Teknologi Pasca 100 Tahun Kebangkitan Nasional. Seminar Nasional Sains dan Teknologi II. Lampung, 17-18 November 2008.

Raj, A., M.K. Jhariya, P. Toppo. 2014. Cow dung for ecofriendly and sustainable productive farming. IJSR. 3: 201-202.

Santosa, B.B., Hasnam, Haryadi, S. Susanto, B.S. Purwoko. 2008. Perbanyakan vegetatif tanaman jarak pagar (Jatropha curcas L.) dengan stek batang: pengaruh panjang dan diameter stek. Bul. Agron. 36(3): 255-262.

Setyani, Y.H., S. Anwar, W. Slamet. 2013. Karakteristik fotosintetik serapan fosfor hijauan alfafa (Medigaco sativa) pada tinggi pemotongan dan pemupukan nitrogen yang berbeda. J. Anim. Agric. 2(1): 86-96.

Sinha. 2009. Earthworm vermicompost: a powerful corp nutrient over the conventional compost and protective soil conditioner againts the destructive fertilizer for food safety and security. J. Agric \& Environ. Sci. 5(S): 01-55.

Siregar, N., D.F. Djam'an. 2017. Pengaruh bahan tanaman terhadap keberhasilan setek kranji (Pongamia pinnata). Pros.Sem. Nas. Masy. Biodiv. Indon. 3(1): 23-27.

Sofyan, A., I. Muslimin. 2007. Pengaruh asal bahan dan media stek terhadap pertumbuhan stek batang tembesu (Fragraea fragarans roxb). Makalah Penunjang pada Ekspose Hasil-hasil Penelitian: Konservasi dan Rehabilitasi Sumberdaya Hutan. Balai Litbang Hutan Tanaman Palembang. Padang, 20 September 2006.

Sukarman, Melati. 2009. Prosedur perbanyakan nilam secara konvensional. http://balitro. litbang.pertanian.go.id. /ind/index.php/id/ 
publikasi/terbitan-khusus/233-monograpnilam. [9 Desember 2016].

Sumarno. 2010. Macam dan dosis pupuk organik terhadap hasil dan kadar antosianin kelopak bunga rosela (Hibiscus sabdariffa). JITA. 7(1): 25-30.

Suradal. 2014. Pembuatan arang sekam sebagai media tanam. http://yogya.litbang. pertanian.go.id/ind/index.php?option=com content\&view=article\&id=780:pembuatanarang-sekam-sebagai-media-tanam-\&catid $=14$ :alsin. [13 April 2016].

Suryaningsih. 2004. Pengaruh jenis zat pengatur tumbuh dan media tanam terhadap pertumbuhan stek lada (Piper nigrum L.). [Skripsi]. UNS Press, Surakarta.

Weaver, R.J. 1972. Plant Growth Substances in Agriculture. Freeman, San Fransisco.

Wulandari, E., B. Guritno, N. Aini. 2014. Pengaruh kombinasi jumlah tanaman per polybag dan komposisi media tanam terhadap pertumbuhan dan hasil tanaman mentimun (Cucumis sativus L.) var. Venus. J. Prod. Tan. 2(6): 464-473.

Yana, Y. 2015. 13 Manfaat daun afrika bagi kesehatan. http://manfaat.co.id/manfaatdaun-afrika-bagi- kesehatan. [14 Maret 2016].

Yeap, S.K., W.Y. Ho, B.K. Beh, W.S. Liang, H. Ky, A. Hadi, N. Yousr, N.B. Alitheen. 2010. Vernonia amygdalina, an ethnoveterinary and ethnomedical used green vegetable with multiple bioactivities. J. Med. Plant. Res. 4(25): 2787-2812.

Yulistyani, W., D.S. Sobarna, A. Nuriani. 2014. Pengaruh jenis setek batang dan komposisi media tanam terhadap pertumbuhan bibit tanaman ara (Ficus carica L.). J. Agric. Sci.1(4): 215-224.

Zuhud, E.A.M. 2009. Potensi hutan tropika indonesia sebagai penyangga bahan obat alam untuk kesehatan bangsa. Jurnal Bahan Alam Indonesia. 6(6). 